\title{
Maria Tymoczko angažeeritud tõlketeadus ${ }^{1}$
}

Anne Lange, Miriam McIlfatrick-Ksenofontov

Juhatades sisse oma loengusarjadest välja kasvanud ja nõnda õpiku väärtusega monograafiat „Enlarging Translation, Empowering Translators“ (2007, „Tõlke avardamine, tõlkija volitamine“), kirjeldab Maria Tymoczko kõigepealt oma lapsepõlvelinna Clevelandi, „Ameerika Ühendriike, mida enam ei ole“. Tema ema oli teise põlve ameeriklasest slovakitar, isa, kelle esivanemad olid küll elanud Ühendriikides üle sajandi, identifitseeris end päritolult Šotimaa ja Walesiga. Ümbruskonnas elasid peamiselt immigrandid, kes polnud oma emakeelest loobunud, igaüks rääkis vähemalt kahte keelt, tavaline oli, et ühe päeva jooksul kuulis ühel tänaval mitut KeskEuroopa keelt, mida kõneldi inglise, tolle paljutõotavate võimaluste keele kõrval, tajudes teravalt, kui asümmeetrilised on emakeele ja kodukultuuri võimalused ja prestiiž, millega argielus peab arvestama, tõlkimata midagi „otse“: tingimusi, mis teevad tõlkevaste vastuvõetavaks või kohatuks, on leegion, kaks keelt on kaks maailma, mis ei kattu kunagi. Sestap küsiti Clevelandis uuelt tuttavalt nime järel targu, mis rahvusest ta on. Harvardi õppima minnes tuli aga teadmiseks võtta, et niisugune küsimus on ülearune, sest seal on kõik „ameeriklased“.

Lugedes seitsmekümnendatel Gideon Toury, Itamar Even-Zohari ja André Lefevere'i töid, sõnastasid need Tymoczkole kogemuse, mis oli talle elust tuttav, ja andsid mõisted, mida ta oli otsinud, kuigi - jäi ka küsitavusi. Kaitsnud kõik oma kraadid Harvardis (BA 1965, MA 1968, PhD 1973) - ajal, mil seal õpetasid ka tõlketeaduse arenguloos olulised kujud Roman Jakobson, W. V. O. Quine ja Anthony G. Oettinger -, on Tymoczko oma kitsamalt erialalt medievist, keskaegse Euroopa kirjanduse uurija ja õpetaja. Uurides lugude rändamist kirjakeeleta rahvaste vahel, sai ta aru, et rääkida sel puhul "tõlkimisest“ on tõlkimise harjumuspärast teoreetilist kontseptualiseerimist ja nüüdisaegseid tõlkenorme silmas pidades mõnevõrra problemaatiline, aga samas - mis oli siis see, mis tõi kas keldi või araabia või ladina lood vanaprantsuse kirjandusse? Nõnda süvenes aastatega keskaegse keldi kirjanduse kõrval huvi ka tõlketeooria vastu, mille ümbermõtestamiseni jõuab ta juba nimetatud raamatus „Tõlke avardamine, tõlkija volitamine“.

Oma lähtekohtade tunnistamine on tõlketeaduses korduv praktika. Näiteks soovib Anthony Pym (1998: x) oma tõlkeloo metodoloogiaraamatus, et uurijate epistemoloogilises positsioneerimises oleks oma annus pihtimuslikkust:

[---] miks peaks keegi esiteks tahtma tõlkelugu koostada. [---] Tõlkelugu koostatakse, et väljendada, käsitleda ja proovida lahendada probleeme, mis mõjutavad meie enda olukorda. See ei tähenda iseenda jultunud projitseerimist minevikule. Vastupidi, minevik on objekt, mis tuleb meie küsimustele vastama panna, mis osutab kategooriatele ja võimalikele lahendustele, millele me varem ei olnud mõelnud. Aga algne lähtekoht on alati

1 Artikli kirjutamist toetasid ETFi grandid nr 8152 ja 8982. 
siin ja praegu. Selles ei maksa endale illusioone teha. Oleviku prioriteet ei ole ainuüksi vältimatu, vaid ka äärmiselt teretulnud; mina olen tõlkeloos tugeva subjektiivse seotuse poolt. Peaksid meie objekti keskel seisma inimesed, tuleb inimesestada ka meie historiograafiline subjektsus.

Nagu eespool tõlgitud Tymoczko artiklist näha, on talle oluline, et tõlketeaduses oleks tõlkimine sotsiaalpoliitiliselt kontekstualiseeritud - nagu see on reaalelus -, sest globaliseeruvas maailmas, mida majandatakse tõlkimisega ühtviisi nii põllu- kui ka loomemajanduses, on oht, et tõlked ja tôlkijad alaväärtustavad ja hävitavad „globaalsega“ lokaalse, nimetades assimileerimist eufemistlikult kultuurivahetuseks. Sestap olgu tunnistatud tõlkijate voli ja vastutus avardada oma puhtfiloloogilist toimekust sotsiaalse tundlikkusega, andes endale aru, et ühiskonda kujundavad ennekõike võimustruktuurid, nii ilmselged ja ametlikud kui ka varjatud. Ja sestap ärgu salaku ka tõlketeadus, et poliitilist seotust, olgu teadlikku või teadvustamatut, on tõlkimisel raske vältida, seda näeb nii tõlke sisu- kui ka väljendusplaanis tõlkelahenduste puhtlingvistilise tasandini välja, mistõttu peab neid lahendusi oskama kontekstualiseerida. Pealegi, tõlkepraktikal kogu maailmas on aastatuhandete pikkune ajalugu, millele iga kultuur peaks söakalt toetuma ja tõlketeaduse peavoolule vastu astuma - kui vaja. Seega esindab Tymoczko 1990. aastatel deskriptiivse tõlketeaduse teises faasis toimunud kultuurilise pöörde temperamentsemat edasiarendust, võimupööret.

Seda esindab ka Lawrence Venuti, tõlketeaduse elav maailmaklassik ja karismaatiline populariseerija Ühendriikides, keda Tymoczko kohtleb oma artiklis ometi enam kui karmilt, mõjudes Venuti populaarsuse ja vaieldamatult efektsete formuleeringute foonil (vt Chalvin 2010: 173) omamoodi võimupöörajana. Aga samas, Venuti mõjukust arvestades on oluline temast võimalikult selgelt ja nüansseeritult mõelda. Oma rangelt keeletoimetatud pika tõlketraditsiooni juures ei saakski me ju võtta võõrapärastava tõlkestrateegia propageerimist iseenesestmõistetavana. Nõnda sai teooriavahenduse rubriiki valitud Venuti kriitika, ja rubriigi mahtu arvestades oli raske leida rahulikumat kirjatööd olgu Tymoczkolt endalt või kelleltki teiselt, mis pikkuselt ka kõne alla tulnuks. Venuti (ja talle soovitustelt üsna lähedase Antoine Bermani) ettepanekute problematiseerijaid on aga teisigi. Näiteks Douglas Robinson (1997b: 136-137) on deformeeritud väljundkeelde tõlkimise puhul palunud mõelda, keda on õigupoolest väärkasutatud, kui me seisame silmitsi keeleliselt vahetult arusaadava, loomulikus keeles veenva tõlkega. Kas tõesti originaali autorit ja tema kultuuri? Või lugeja võimet taibata, et näiteks Salman Rushdie ei ole eesti kirjanik? Ja kelle sügavamaid eetilisi tarbeid on teenitud siis, kui anda välja keeleliselt iseäratsev tõlge, mis teksti poeetilise pärisstruktuuri summutab? Kas Salman Rushdie soovi olla tõepoolest Teine?

Defineerides tõlget avatud klastermõistena - et teha see kasutatavaks reaalses tõlkepraktikas läbi aegade ja rahvusvahelises tõlketeaduses ka väljaspool Vana ja Uue Maailma Euroopa kultuure -, uurib Tymoczko (2007: 107-139) tõlke tunnuseid raamimise strateegiaga. Rääkides raamimisest, panustab ta tavakeelele ega pea silmas lingvistikas või sotsiaalteadus- 
tes välja töötatud spetsiifilisemaid tähendusi. Raamimine on katse mõista nähtust väljastpoolt, teise kontsepti abil, mis mõistet osaliselt iseloomustab - nagu Lefevere (1992), kui ta analüüsis tõlkimist kui ümberkirjutust, või Eco (2004), kui ta räägib tõlkimisest kui läbirääkimistest. Tymoczko raamid tõlkele kui produktile ja protsessile on üllatuslikud selles mõttes, et ta tõstab raami staatusesse vanad tuttavad atribuudid, mida on öeldistäitena tõlke kohta ikka kasutatud - representatsiooni, ülekande ja transkulturatsiooni -, sest kultuuriuuringute kontekstis on neist kõigist saanud kultuurivahetuse ja kultuurilise filtreerimise liigid (mode). Taas, panustades loomulikule keelele ja kirjakeele seletavatele sõnaraamatutele, ei seo ta end ühegi olemasoleva metodoloogilise repertuaariga ega pea ühegi puhul kolmest silmas teistes distsipliinides välja kujunenud tähendusi, vaid seletab kultuurivahetuse võimalusi tavakeeles. Representation on (Oxfordi suure seletussõnaraamatu järgi) kujutis, kuvand, pilt, eriti kui see annab edasi konkreetset vaatenurka või muljet, et mõjutada arvamust või tegu. Nii võiks iga üksiktõlke puhul küsida, missuguse representatsiooni, missuguse ettekujutusega on tegemist ja mis eesmärki see teenib (sest representatsioonis on tugev annus intentsionaalsust).

Ülekanne (transmission või transfer) on osaliselt seletatud oma kollokatsioonidega: ühelt teisele üle kandma nagu vere- või pangaülekandes. Lisaks on transfer ka üleandmine nagu vara puhul, ja edasiandmine, kui rääkida teadmistest. Selles kultuurivahetuse viisis, erinevalt eelmisest (ennekõike semiootilisest, märgilise tähendusega representatsioonist), ei ole rõhutatud ülekandja subjektiivsust; ülekandmisel järgitakse tavaliselt mingeid harjumuspäraseid protseduure, kuigi nii pärimuse kui ka raha ühelt teisele andmise viise on iseenesest harilikult mitu. Ent ka ülekande juures ülekantav muutub seoses ülekandmise materiaalsete ja tehniliste paratamatustega: teleülekanne ei ole elav esitus, eurod võib välja võtta Rootsi kroonides (ja muutunud vormil on omakorda erinev sümboolne väärtus).

Transculturation, tõlkeartiklis joone all kord juba seletatud mõiste, mis tuli inglise keelde hispaania transculturación'ist ja Kuuba kultuuri uurimise näitest, kannab eesti kirjakeele seletussõnaraamatule toetudes akulturatsiooni, vastastikuse kultuurivahetuse, kultuuri hübridiseerumise sisu, ja nagu eelmistegi kategooriate puhul, ei ole silmas peetud ainult verbaalse materjali vahetust. Transkulturatsioon hõlmab uskumuste ja tõekspidamiste, kunstiliikide ja vormide, tehnoloogiate ja tööriistade, toidu ja rõivaste ülevõtmist ja kodustamist. Erinevalt representatsioonist ja ülekandest nõuab transkulturatsioon laenatud kultuurivormide toimimist (performatiivsust) vastuvõtvas kultuuris kuni naturaliseerimiseni välja, nii et nende algupära tuhmub ja need arvatakse omaks. Üks näide transkulturatsioonist kirjasõnas on Tymoczkol Joyce'i „Ulysses“, mis kasutab vanaiiri kirjanduse vormielemente lugejale nende iiri päritolust teada andmata. Ega Tammsaaregi oma loomingus kasutatud vormielementide päritolule osuta, ja ka temal on mõni neist tõlkeline (Haug 2007: 1878, Lange 2009). Traditsioonilisele tõlke mõistele lähemale tulles võib transkulturatsioonina kirjeldada Ezra Poundi hiina luule tõlkeid või uute värsimõõtude ja -vormide tõlkimist eesti keelde: silbilist või puhtkvantiteerivat värsisüsteemi, haiku või limeriku vormi kasutatakse eesti tõlke-, aga ka originaalluules. 
Konkreetsetes tõlgetes ja ka konkreetsel ajal on kultuurilise filtreerimise kolm viisi esindatud erineval määral, osaliselt ja fragmentaarselt: konkreetne kultuuriline ja ajalooline kontekst loob erinevaid võimalusi ja sunnib peale erinevaid kitsendusi. Miks on Eesti 20. sajandi alguse tõlked nii erinevad sajandi lõpu tõlgetest? Seda saab kirjeldada Toury tõlkenormide abil, saab kirjeldada, võttes raamiks eesti kirjakeele või kultuuriloo, ja saab kirjeldada, kasutades Tymoczko laiemaid kategooriaid, mis aitavad, vastavalt tõlke iselaadile, iseloomustada tõlget kujundanud kultuurilist kokkupuudet tõlke igal tasandil. Tähtis on, et raam ei oleks olulisem konkreetsest tõlkenähtusest endast, mille rahuldavaks seletamiseks ei piisa ühest raamist kunagi. Mis on aga Eestis tänu Peeter Toropi totaaltõlke õpetusele koduse kasvatuse $A$ ja 0.

Tymoczko töö suurim huvipakkuvus meile ehk on, et lisaks uurimistöö struktuuri ja mõistestiku problematiseerimisele on ta liri tõlkelugu kirjutades tegelnud ka empiirilise uurimistööga, uurides tõlkelugu maal, mis on olnud koloniseeritud aastasadu; tõlkimine pole seal saanud olla kahe võrdse kultuuri vaba kultuurivahetus ega tõlkija lähtekultuuri põhjalik ekspert, kes teeb tõlkega kättesaadavaks oma professionaalse teadmise. Tõlkimist on lirimaal nagu Eestis kasutatud sageli strateegiliselt teistel eesmärkidel, tõlkega on ehitatud omakultuuri, võideldud iiri kultuuri kas anglitseerimise või tarastamise vastu, ja tõlkijad on olnud „nähtavad“, avaliku elu tuntud tegelased. Kui kirjutada niisuguse maa tõlkelugu, ei saa sellest välja arvata meilegi nii tuttavaid ümberjutustusi, mugandusi jms, sest nii jääksid väärtustamata tõlked, mis vastustasid valitsevat polariseeritud kultuurisituatsiooni. Koloniseeritud rahvale on tõlge kõigepealt „tegu“ ja siis alles „tekst“; kultuuride võimu asümmeetria korral võib üksnes tõlkimise tõsiasi ollagi tõlkes kõige olulisem.

Ehkki liri tõlkelugu ilmus iseenesest vastuolulise pealkirjaga „Translation in a Postcolonial Context: Early Irish Literature in English Translation“ (Tymoczko 1999b, „Tõlge postkoloniaalses kontekstis: vanaiiri kirjandus ingliskeelses tõlkes"), on Tymoczko kaugel tõlkijate poliitilise aktiivsuse mütologiseerimisest; ta ei taha taandada tõlkelugu tervikuna võimuvõitlusele. Küll aga annab ta endale (suures osas Pierre Bourdieu habitus'e mõistele toetudes) aru tõlkijate volist representeerida või representeerimata jätta performatiivse väärtusega kultuurilisi erinevusi, kasutades esimesel juhul näiteks paratekstilisi võimalusi ja teisel kultuurierinevuste assimileerimist. Tõlkimine seisnebki kultuurierinevuste vahendamises (vt Bhaba 1994: 228); kuidas tõlkija seda teeb, see määrab tema poliitilise positsiooni ja meisterlikkuse.

Kultuurist soovitab Tymoczko nii tõlkijal kui ka tõlketeadlasel mõelda holistlikult (vt ka Sarv 2000, kus holismi mõistet on kasutatud setu kultuuri uurimisel), s.o võtta arvesse kultuuri kõiki tõlgitava tekstiga seotud tahke, selmet keskenduda ainult materiaalsetele erinevustele. Kultuuri tekstualiseeritud ilmingud lähtetekstis on tõlkimisel küll olulised, aga niisama tähtis on ka lähtekultuuri sotsiaalsete süsteemide sisemine dünaamika, see, missuguseid religioosseid, soolisi, põlvkondlikke jm hoiakuid ja väärtusi tekst peegeldab, neid kas jagades või kahtluse alla seades. Viimase lause võib kirja panna ka väljundkultuuri kontekstis. Tymoczko kultuuri holistlikul tõlkel on sarnasusi totaaltõlke (Torop 1995) ja "tiheda tõlke“ 
(Appiah 2000, Geertz 2007) mõistega ning funktsionaalsete tõlketeooriatega (Nord 1997). Tema enda sõnavara juurde jäädes (Tymoczko 2007: 238-249) on tõlkestrateegia valimise ja hindamise eel otstarbekas mõelda kultuuri tunnusmõistetele, võtmesõnadele, kontseptuaalsetele metafooridele, käibivatele diskursustele, kultuuripraktikatele, paradigmadele, mis reguleerivad näiteks naljast arusaamist või argumenteerimistavasid, ja markeritele, mis osundavad kas käitumisnormidele või kirjanduslikele žanritele. Neid kõiki arvesse võttes saab kultuuriline representatsioon, ülekanne või transkulturatsioon väljundtekstis olla sihipärasem ja sidusam. Tõlke eetilisust lähte- ja väljundkultuuri holistlik tajumine muidugi ei garanteeri: kui tõlkija lähteteksti unikaalsusest ei hooli ega kaalu tõlke ajastamisega seotud riske, on tulemuses ebaõiglust ja sageli kahetsusväärsust.

Globaalset teooriat edendades on Tymoczkole oluline viia suured üldistused kokku konkreetse, spetsiifilise, ajas ja ruumis kontekstualiseeritud materjaliga. Tõestada lokalismi olulisust siinkohal oleks lahtisest uksest sissemurdmine; kõige veenvamalt teeb seda pealegi Tymoczko 1999. aasta monograafia, kus on reljeefselt kirjas üks peatükk liri tõlkeloost. Raamatu pealkirja esimene pool „Tõlge postkoloniaalses kontekstis“ näitab, et tegemist on tõlketeaduse postkoloniaalse pöörde saaduse, järjekordse käsitlusega tõlke rollist 20. ja 21. sajandi dekoloniseerimisprotsessides. Uurimus näikse viivat meid maakera teise nurka Vicente Rafaeli (1993), Eric Cheyfitzi (1991) ja Tejaswini Niranjana (1992) jälgedes, kes on analüüsinud ja problematiseerinud seda, kuidas on tõlge kanaliseerinud impeeriumi ja impeeriumile vastu astunud vastavalt Filipiinidel, Põhja- ja Lõuna-Ameerikas ja Indias. Sedapuhku on uurija end sisse seadnud keskaegse iiri kirjanduse tõlkimise nišis. Ent Tymoczko nišš osutub avaramaks kui tema senistel eelkäijatel, sest ta käsitleb varasemaid tegematajätmisi ja ülearuseid üldistusi - puudusi, millele on tähelepanu juhtinud Douglas Robinson. Robinson (1997a: 108-113) on kolme varasemat käsitlust arvustades väitnud, et hoolimata uute andmete esitamise ja postkoloniaalse tõlke asjatundlikuma arutelu algatamise väärtuslikust panusest on kõik need ebapiisava teoreetilise raamistiku ja tõlkeretoorika harjumuspärase keele ja mõistete ohvrid. Osaliselt seostab ta seda tõsiasjaga, et „postkoloniaalne tõlketeooria on ikka veel lapsekingades“, arvamusega, mida kaks aastat hiljem kordab Tymoczko (1999a: 19), viidates „adekvaatse sõnavara“ puudumisele postkoloniaalses kirjanduskriitikas; ometi on paljud tõlketeoreetikud postkoloniaalse tõlke uurimisel oma mõisted ja (siis ka?) vaatenurga võtnud just sealt. Kui samal teemal kirjutamiseni jõuab Tymoczko, tunneb ta, et sealjuures peaks arendama ka metakeelt, et see oleks oma ülesannete kõrgusel. Nõnda on Tymoczko vanaiiri kirjanduse spetsiifika ja selle ingliskeelsete tõlgete põhjalike juhtumiuuringute kavandamisel silmas pidanud kahte eesmärki: käia läbi konkreetne postkoloniaalne tõlketrajektoor ja jõuda tõlketeooria avarama rekontseptualiseerimiseni. Tulemuseks on tõlkepraktikast lähtuv tôlketeooria, kus tôlge on ja jääb „teadmise kujunemise paigaks“ (Tymoczko 1999b: 294).

Mida teeb Tymoczko oma juhtumiuuringutes õigupoolest uut või teisiti? Kuidas õnnestub tal neid esitada nii, et need ületavad tõlkeloo illustreeriva lisandi piiri ja heidavad sama valguse teisele kohale suunamise asemel pigem uut valgust? Esiteks on tema meetodiks „hooli- 
kalt põhjalik uurimine“, mida ta võrdleb (1999b: 32) Joyce'i „piinliku väiklusega“ (scrupulous meanness), nagu viimane ise on oma kirjutamisstiili nimetanud, s.o nähtu ülitäpse ja selge dokumenteerimisega ilma autoripoolse sekkumise või kallakuta, nii et materjali tõeline loomus ja tõekspidamised saaksid välja tulla. Vaatame, kuidas seda on tehtud küsimuses, mis on tõlketeaduses üks keerulisemaid ja vaieldavamaid - kuidas tõlkida kultuuri? -, mille Tymoczko tõstatab oma vanaiiri kirjanduse tõlkelugu käsitleva monograafia (1999b) kuuendas peatükis „Cú Chulainni atribuudid: kultuuri tõlge postkoloniaalses kontekstis“. Kuidas-küsimuse käsitlemisel on postkoloniaalses tõlketeaduses üldiselt kirjutatud uurimusi, mis dokumenteerivad kultuuri vääriti esitamist, moonutamist või mahavaikimist, s.o tõlke tajutud ebaõnnestumisi. Tymoczko loogika järgi peaks see viima uurija küsimuseni, missugune võiks olla antud kultuuri „mitteimperiaalne“ (ja seega õnnestunud?) tõlge. Uuele küsimusele vastamiseks tuleb originaaltekstis tuvastada kultuuri võtmeelemendid, mis markeerivad selle kuulumise bengali, tagalogi, iiri, vanaiiri või mõnesse muusse kultuuri. Tymoczko nimetab neid „tunnusmõisteteks“ (signature concepts); nende roll nii kultuuri diskursustes ja praktikates kui ka kirjanduslikes tekstides on keskne ja korduv (samas, 166). Kultuuri määravate joonte üheselt mõistetav tuvastamine on aga üldteadaolevalt raske, ka sellepärast, et need on dünaamilised ja harva selgepiirilised. Tymoczkole omase didaktilisusega aitab ta edasi näite varal, valides vanaiiri kultuurist välja viis iirikeelset tunnusmõistet, mis on Cú Chulainni, „Táin Bó Cúailnge“ kangelase atribuutide loeteludes korduvad: síd ('maailma üleloomulik teine pool ja selle asukad'), ríastrad ('lahinguraevust moondunud'), ces ('tuhudega võrreldav teovõimetus lahingu ajal'), táin ('kariloomade röövimine') ja geis ('sisemine või väline käsk või keeld'), defineerides kõiki neid mitme lõigu pikkuses. Tunnusmõisted määravad lõppkokkuvõttes juhtumiuuringu fookuse, parameetrid ja väärtuse, sest vaadata, kuidas tõlkijad on nendega ümber käinud, on uurijale jõukohane ülesanne, mille saaduseks on valdkonna teistele asjatundjatele mõttekas keskendatus. Tegelikult tähendab see globaalse küsimuse (kuidas tõlkida kultuuri) rajamist lokaalse praktika eripärale.

Uurimine läheb aga veelgi sügavamale, lokaalsest fundamentaalse juurde, sest tunnusmõistete tuvastamine sisaldab eneses põhimõttelisemat küsimust: mis on kultuur? Selle ükskõik kui ettevaatlik defineerimine annab juhtumiuuringule sidususe.

Niisugune siis on Tymoczko uurimistöö, mis püüab veenda 1) küsimuste esitamisega, mis lähevad järjest täpsemaks ja samal ajal kõnealuse kultuuri spetsiifikat järjest paremini arvestavaks (et vähendada impulsiivse ja ülearuse üldistamise või totaliseerimise ohtu), ja 2) kultuuriga üldiselt seotud mõistete problematiseerimisega (et jääda täpseks ja sidusaks). Tavaliselt kuhjatakse tõlkeuuringutes kokku näiteid tõlkija tõlkevalikutest, millest osa seejärel kategoriseeritakse, et lõpuks mõnda neist esitada tõendusmaterjalina originaali spetsiifilisest ümberkirjutamisest või originaaliga manipuleerimisest (nt Lefevere 1985, ja 1992). Mõlemal juhul toetutakse eeldusele, et uus tekst on mingis mõttes originaali versioon; Tymoczko arvab, et ühtlasi on see ka e t t e ku j u t u s originaalist, ettekujutus, mille ta rekonstrueerib, jälgides sõnahaaval tõlkevalikuid, mis osutuvad ideoloogiliselt määratuks. 
Jälgides, kuidas viit väljavalitud tunnusmõistet on koheldud kolmes "Táin Bó Cúailnge“ tõlkes (1878-1880, 1902, 1969), nimetab Tymoczko tõlkijate strateegiaid vastavalt kas assimileerivaks, dialektiliseks või võõritavaks (ostranie). Seejärel seob ta strateegia koloniseerijate ja koloniseeritute tollaste suhete konkreetse etapiga iiri rahvuslikus enesemääramistaotluses. Mõelgem táin'i, kariloomade röövimise/tõmbamise näitele. Vanaiiri karjakasvatuskultuuris, kus loomadega mõõdeti jõukust ja staatust, tähendas röövimine võimu, au ja kangelastegu, nõnda et see on iiri kirjanduse peamise kangelasloo iseenesestmõistetav teema. Standish O'Grady 1878.-1880. aasta tôlkes saab táin'ist pärisnimi Tân, väesalga nimetus, sest loomade röövimine ei oleks sobinud O'Grady ja tema ingliskeelse lugejaskonna keskaegsest rüütliromaanist pärit ettekujutusega kangelaslikkusest, mis on O'Grady legendide kogumikus „History of Ireland: The Heroic Period“ („Kangelaste ajastu lirimaa ajaloos“) rüütlite ja õukondlaste kanda. O'Grady tahtis öelda: see on teile tuttav lugu, mis on muide iiri lugu; tema eesmärk oli iiri kirjanduse jõudmine ingliskeelsele kaardile. Leedi Gregory 1902. aasta tõlkes on táin 'sõda'; militaarne kangelaslikkus vastas inglise normidele ja iiri rahvuslikele taotlustele. Kinsella 1969. aasta tõlkes saab aga táin'ist määrava artikliga „The Táin“, täieõiguslik pealkiri täiskasvanute kangelasloole, mis seisab oma vastleitud lingvistilises vastastikkuses õlg õla kõrval teiste rahvuseeposte, „Odüsseia“ ja „Kalevalaga“; Kinsella tahtis öelda: see on ingliskeelne iiri eepos.

Üksik näide ühest juhtumiloost saab anda ainult põgusa ettekujutuse Tymoczko meetodist ja tulemustest; teistes juhtumiuuringutes vaatleb ta tõlke teisi aspekte (nt sisu, vormi, žanrit), rõhutades, et igaüks neist on ainult üks parameeter, mille järgi tõlkestrateegia üle otsustada. Ta uurib üldplaanis, samm-sammult ja sõnahaaval, kuidas avaldub tõlkes tõlkija ettekujutus tekstist, näidates, et klassikalise teksti (uus)tõlked on seotud rahvuse ja kultuuri (ümber)mõtestamisega. Nõnda distantseerub Tymoczko nendest, kes peavad ilukirjanduslikku tõlget poeetiliseks käeharjutuseks, poeetika asendamiseks poeetikaga, mis on endastmõistetavalt metafoorne. Ka näiteks Henri Meschonnic, kes kirjutab samuti 1999. aastal, möönab (1999: 80) tõlke ideoloogilisust, kuivõrd iga tõlge peegeldab tõlkija ettekujutust sellest, mis on kirjandus ja mida keelega saab või ei saa teha, s.o keeleideoloogia, kirjandusideoloogia ja oma aja teadmiste (les savoirs du temps) vahelist suhet. Kui viimane mõistena ongi ebamäärane, annab see märku Meschonnici nõutusest tõlkimise igakülgse, lingvistilisi, kirjanduslikke, ajaloolisi ja antropoloogilisi diskursusi sünteesiva käsitluse puudumise üle. Tymoczko ajalooline tõlkepoeetika peaks seda lünka täitma.

\section{Ki r j a n d u s}

Appiah, Kwame Anthony 2000 [1993]. Thick Translation. - The Translation Studies Reader. Ed. L. Venuti. London, New York: Routledge, Ik 417-429.

Bhaba, Homi K. 1994. The Location of Culture. London: Routledge.

Chalvin, Antoine 2010. Lünkade täitmine. - Vikerkaar, nr 10-11, Ik 173-176. 
Cheyfitz, Eric 1991. The Poetics of Imperialism: Translation and Colonization from „The Tempest" to „Tarzan“. New York: Oxford University Press.

Eco, Umberto 2004. Mouse or Rat? Translation as Negotiation. London: Phoenix.

Geertz, Clifford 2007 [1973]. Tihe kirjeldus: tõlgendava kultuuriteooria poole. TIk T. Pakk-Allmann. - Vikerkaar, nr 4-5, Ik 78-110.

Haug, Toomas 2007. A. H. T. lahkumine Koitjärvelt. Lapse sünd „Kõrboja peremehes“. - Looming, nr 12, Ik 1876-1888.

Lange, Anne 2009. On the Economy of Translating Lord Jim. - Interlitteraria, No. 14, Ik 349-368.

Lefevere, André 1985. Why Waste Our Time on Rewrites? The Trouble with Interpretation and the Role of Rewriting in an Alternative Paradigm. - The Manipulation of Literature: Studies in Literary Translation. Ed. T. Hermans. London: Croom Helm, Ik 215-243.

Lefevere, André 1992. Translation, Rewriting, and the Manipulation of Literary Frame. London, New York: Routledge.

Meschonnic, Henri 1999. Poétique du traduire. Paris: Verdier.

Niranjana, Tejaswini 1992. Siting Translation: History, Post-Structuralism, and the Colonial Context. Berkeley, Los Angeles: University of California Press.

Nord, Christiane 1997. Translation as a Purposeful Activity: Functionalist Approaches Explained. Manchester: St. Jerome.

Pym, Anthony 1998. Method in Translation History. Manchester: St. Jerome.

Rafael, Vicente L. 1993. Contracting Colonialism: Translation and Christian Conversion in Tagalog Society under Early Spanish Rule. Durham: Duke University Press.

Robinson, Douglas 1997a. Translation and Empire: Postcolonial Theories Explained. Manchester: St. Jerome.

Robinson, Douglas 1997b. What is Translation? Centrifugal Theories, Critical Interventions. Kent, Ohio, London, England: The Kent State University Press.

Sarv, Vaike 2000. Setu itkukultuur. Tampere, Tartu: Eesti Kirjandusmuuseum.

Torop 1995 = Пеэтер Тороп, Тотальный перевод. Тарту: Издательство Тартуского Университета.

Tymoczko, Maria 1999a. Post-colonial writing and literary translation. - Post-Colonial Translation: Theory and Practice. Eds. S. Bassnett, H. Trivedi. London, New York: Routledge, Ik 19-40.

Tymoczko, Maria 1999b. Translation in a Postcolonial Context: Early Irish Literature in English Translation. Manchester: St. Jerome.

Tymoczko, Maria 2007. Enlarging Translation, Empowering Translators. Manchester, Kinderhook (NY): St. Jerome.

Anne Lange - PhD kirjandusteaduses. Tallinna Ülikooli tõlketeooria dotsent.

E-post: anne.lange@tlu.ee.

Miriam Anne Mcllfatrick-Ksenofontov - Tallinna Ülikooli doktorant. Töötab Tallinna Ülikooli inglise filoloogia osakonnas lektorina; tõlkinud inglise keelde Doris Kareva, Asko Künnapi, Inderk Hirve, Ülar Ploomi, fs-i jt luulet.

E-post: miriammcilfatrick@yahoo.com. 